\title{
Association of Venous Angioma and Atypical Meningioma
}

\author{
-Case Report- \\ Takashi Kamezawa, Tetsuro Shimozuru, Masaki NiIRo, Ken Hayashi, \\ and Jun-ichi KURATSU
}

Department of Neurosurgery, Faculty of Medicine, Kagoshima University, Kagoshima

\begin{abstract}
A 67-year-old male presented with an atypical meningioma arising from the right tentorium associated with a venous angioma in the left cerebellar hemisphere. The venous angioma was detected incidentally during examinations for the brain tumor. The brain tumor was removed completely and the venous angioma followed conservatively. Venous angiomas associated with brain tumors should be followed conservatively, as the clinical significance and surgical indications are unclear.
\end{abstract}

Key words: venous angioma, magnetic resonance imaging, atypical meningioma, brain tumor

\section{Introduction}

Cerebral vascular malformations can be classified as cavernous angiomas, capillary telangiectases, arteriovenous malformations, and venous angiomas. ${ }^{7,814)}$ Venous angiomas are the most common vascular malformation identified on radiographic studies as well as in autopsies. A series of more than 8200 craniospinal magnetic resonance (MR) images included 50 venous angiomas. ${ }^{4)}$ These malformations are usually detected incidentally on routine MR images and their clinical significance is controversial. ${ }^{1,3,4,6,12,13,17-19,211}$

The association of venous angioma and brain tumor is rare. We report a patient with an atypical meningioma arising from the right tentorium that was associated with a venous angioma in the left cerebellar hemisphere which was detected incidentally during examinations for the brain tumor.

\section{Case Report}

A 67-year-old male presented with a 3-month history of left-sided homonymous hemianopsia. Neurological examination revealed left-sided homonymous hemianopsia and mild left hemiparesis. Computed tomography (CT) revealed a hyperdense area in the right occipital lobe and a small hyperdense nodule in the left cerebellar hemisphere. Postcontrast CT

Received February 1, 1999; Accepted June 2, 1999 demonstrated a heterogeneously enhanced mass lesion in the right occipital lobe and an enhanced nodule in the left cerebellar hemisphere. MR imaging with gadolinium-diethylenetriaminepenta-acetic acid demonstrated the occipital lesion as a heterogeneously enhanced mass attached to the tentorium, without perilesional edema. A cerebellar lesion was detected at the site of medullary and draining veins (Fig. 1). Left vertebral angiography showed a

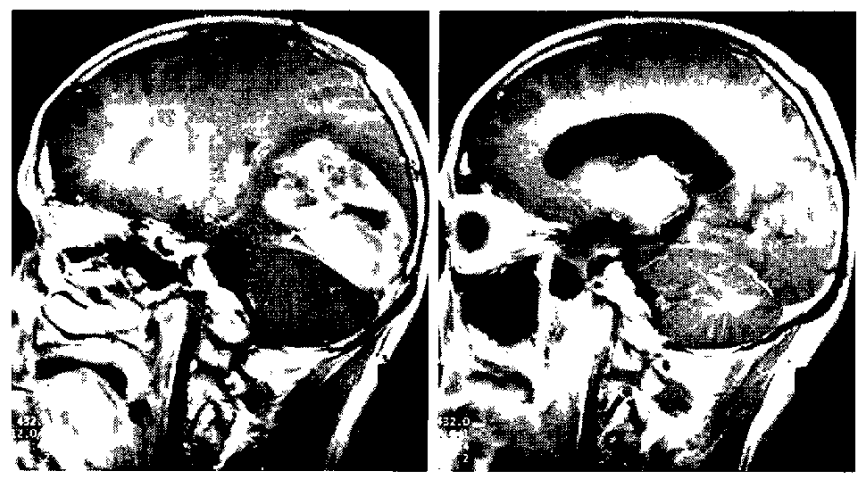

Fig. 1 Magnetic resonance images with gadolinium-diethylenetriaminepenta-acetic acid revealing a heterogeneously enhanced lesion without peritumoral edema in the right occipital lobe, attached to the posterior portion of the tentorium (left), and the typical features of venous angioma in the left cerebellar hemisphere (right). 


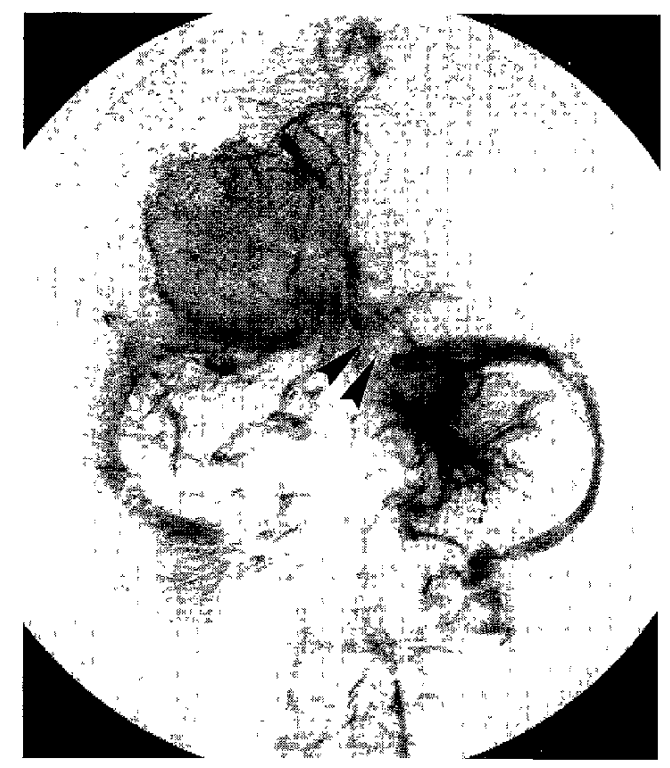

Fig. 2 Left vertebral angiogram (venous phase) demonstrating a tumor stain in the right occipital lobe and venous angioma in the left cerebellum. Multiple dilated medullary veins converge on the draining vein that drains into the left transverse sinus. Note the absence of filling of the left transverse sinus between the confluence and a draining point of the venous angioma (arrowheods).

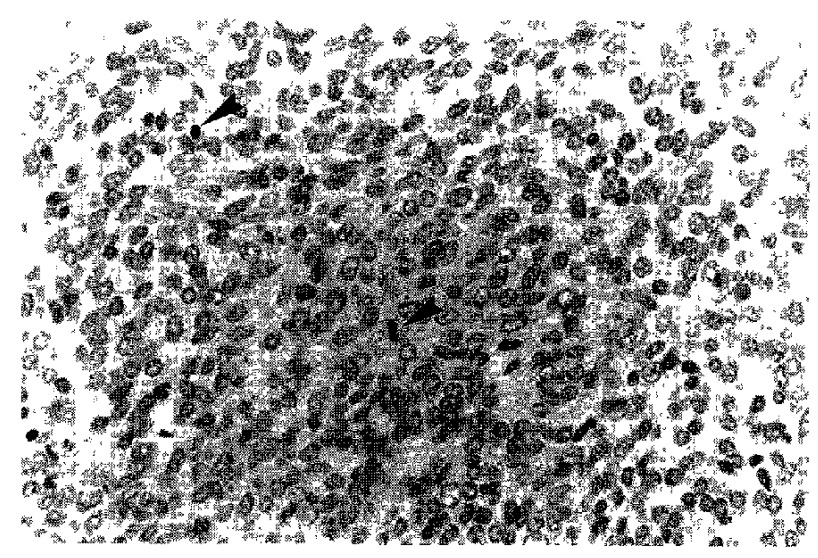

Fig. 3 Photomicrograph of the surgical specimen showing diffuse proliferation of meningothelial cells with frequent mitoses (arrowheads). However, there is no necrosis or brain infiltration. HE stain, original magnification $\times \mathbf{4 0 0}$.

tumor stain in the right occipital lobe, and dilated medullary veins in the left cerebellar hemisphere draining into the left transverse sinus. There was no filling of the left transverse sinus between the con- fluence and the point of drainage from the venous angioma (Fig. 2).

Right occipital craniotomy was performed and the tumor was totally removed (Simpson's grade 2). Histological examination of the specimen showed diffuse proliferation of meningothelial cells with frequent mitoses (Fig. 3). However, there was no necrosis or brain infiltration. Immunohistochemical staining showed the tumor cells were positive for epithelial membrane antigen and vimentin. Based on these observations, the diagnosis was atypical meningioma.

Postoperatively, the left-sided homonymous hemianopsia was ameliorated, and the mild left hemiparesis disappeared completely. One month after surgery he was discharged from the hospital. The venous angioma was followed conservatively.

\section{Discussion}

The association of venous angioma and brain tumor is rare and the true incidence remains unclear. ${ }^{3,6,11,17,19)}$ Including our patient, only 15 cases of brain tumor associated with venous angioma have been reported (Table 1). ${ }^{3,6,12,18,20,21)}$ Information was available in 13 cases, seven males and six females aged from 14 to 73 years (mean 46.1 years).

The venous angiomas and brain tumors were both located supratentorially in six cases and infratentorially in three. In another four patients including ours, one lesion was supratentorial and the other infratentorial. The associated brain tumors were meningioma in six cases, including one atypical meningioma, astrocytoma in three, acoustic schwannoma in two, glioblastoma in two, medulloblastoma in one, and ependymoma in one.

The etiology underlying the association of venous angioma and brain tumor is unclear. The venous angiomas were incidentally detected during examinations for associated brain tumors in 14 of 15 cases. In Case 1, a glioblastoma developed 1 year after the detection of the venous angioma in the same area. ${ }^{121}$ Venous angiomas are congenital malformations or anomalies of the normal venous drainage, so we think that the coexistence of venous angiomas and brain tumors is incidental.

Surgical planning for patients with this association should consider the clinical significance of the cerebellar venous angioma. Cerebral venous angiomas have been implicated in epilepsy, progressive neurological deficits, and hemorrhage, but their clinical relevance remains controversial. ${ }^{13,4,6,12,13,17-19,21)}$ Venous angiomas located in the cerebellum are frequently associated with various symptoms such as gait ataxia, diplopia, and dizzi- 
Table 1 Cases of association of venous angioma and brain tumor

\begin{tabular}{|c|c|c|c|c|c|}
\hline $\begin{array}{c}\text { Case } \\
\text { No. }\end{array}$ & Author (Year) & Age/Sex & $\begin{array}{l}\text { Associated tumor } \\
\text { histology }\end{array}$ & Location of tumor & $\begin{array}{c}\text { Location of venous } \\
\text { angioma }\end{array}$ \\
\hline 1 & Rigamonti et al. [1988) ${ }^{12]}$ & $31 / \mathrm{M}$ & glioblastoma & rt frontal lobe & rt frontal lobe \\
\hline 2 & Wilms et al. $(1990)^{21]}$ & unknown & astrocytoma & lt frontal lobe & cerebellum \\
\hline 3 & & unknown & astrocytome & rt parietal lobe & cerebellum \\
\hline 4 & Wilms et al. $(1992)^{20]}$ & $49 / F$ & schwannoma & lt $\mathrm{CP}$ angle & lt cerebellar hemisphere \\
\hline 5 & & $35 / \mathrm{M}$ & schwannoma & rt $\mathrm{CP}$ angle & rt cerebellar hemisphere \\
\hline 6 & Uchino et al. (1992) & $14 / F$ & medulloblastoma & cerebellar vermis & It cerebellar hemisphere \\
\hline 7 & & $44 / F$ & meningioma & rt sphenoid ridge & it frontal lobe \\
\hline 8 & & $66 / F$ & meningioma & rt occipital lobe & rt frontal lobe \\
\hline 9 & & $48 / \mathrm{M}$ & meningioma & lt occipital lobe & lt temporo-parietal lobe \\
\hline 10 & & $31 / \mathrm{M}$ & astrocytoma & rt frontal lobe & lt frontal lobe \\
\hline 11 & & $29 / \mathrm{M}$ & ependymoma & lt parietal lobe & rt temporo-occipital lobe \\
\hline 12 & Crecco et al. $[1995)^{3]}$ & $51 / \mathrm{F}$ & meningioma & unknown & frontal lobe \\
\hline 13 & & $61 / F$ & meningioma & unknown & parietal lobe \\
\hline 14 & Kanai and Yamada [1998] ${ }^{6]}$ & $73 / \mathrm{M}$ & glioblastoma & lt frontal lobe & rt frontal lobe \\
\hline 15 & Present case & $67 / \mathrm{M}$ & atypical meningioma & rt occipital lobe & lt cerebellar hemisphere \\
\hline
\end{tabular}

CP: cerebellopontine.

ness, even in the absence of marked hemorrhage ${ }^{2,5,9,10)}$ The risk of hemorrhage may be greater in patients with lesions in the posterior fossa than in those with lesions in other areas, ${ }^{6,13,15,18)}$

The natural history of venous angiomas is relatively benign. ${ }^{4}$ Significant symptoms attributable to venous angiomas are rare and surgical resection of these lesions is rarely indicated..$^{1,413,16,17\}}$ A patient with a venous angioma of which the draining vein was ligated at surgery died during the operation from brain infarction. ${ }^{17)}$ Therefore, an associated asymptomatic venous angioma incidentally detected in a patient with a brain tumor should be managed conservatively, irrespective of the location.

\section{References}

1) Awad IA, Robinson JR, Mohanty S, Estes ML: Mixed vascular malformations of the brain: clinical and pathogenetic considerations. Neurosurgery 33: 179188,1993

2) Beatty RM, Zervas NT: Stereotactic aspiration of a brain stem hematoma. Neurosurgery 13: 204-207, 1983

3) Crecco M, Floris R, Vidiri A, Squillaci E, Sergiacomi GL, Mattioli M, Simonetti G, Squillaci S: Venous angiomas: plain and contrast-enhanced MRI and MR angiography. Neuroradiology 37: 20-24, 1995

4) Garner TB, Curing OD Jr, Kelly DL Jr, Laster DW: The natural history of intracranial venous angiomas. J Neurosurg 75: 715-722, 1991

5) Jellinger K: The morphology of centrally-situated angiomas, in Pia HW, Gleave JRW, Grote E (eds): Cerebral Angiomas: Advances in Diagnosis and Ther- apy. New York, Springer-Verlag, 1975, pp 9-18

6) Kanai H, Yamada $K$ : Association of cerebral venous malformation with glioblastoma. Neurol Med Chir (Tokyo) 38: 738-742, 1998

7) Malik GM, Morgan JK, Boulos RS, Ausman JI: Venous angiomas: an underestimated cause of intracranial hemorrhage. Surg Neurol 30: 350-358, 1988

8) McComick WF: The pathology of vascular ["arteriovenous") malformations. J Neurosurg 24: 807816, 1966

9) McComick WF: Pathology of vascular malformations of the brain, in Wilson CB, Stein BM (eds): Intracranial Arteriovenous Malformations. Baltimore, Williams \& Wilkins, 1984, pp 234-245

10) Numaguchi $Y$, Kitamura $K$, Fukui M, Ikeda J, Hasuo K, Kishikawa T, Okudera T, Uemura K, Matsuura K: Intracranial venous angiomas. Surg Neurol 18: 193202, 1982

11) Partain CL, Guinto FC, Scatliff JH, Limbacher J, Janicki $P$, Heindel CC: Cerebral venous angioma: correlation of radionuclide brain scan, transmission computed tomography and angiography. J Nucl Med 20: 1166-1169, 1979

12) Rigamonti D, Spetzler RF, Drayer BP, Bojanowski WM, Hodak J, Rigamonti KH, Plenge K, Powers M, Rekate $\mathrm{H}$ : Appearance of venous malformations on magnetic resonance imaging. J Neurosurg 69: 535539,1988

13) Rigamonti D, Spetzler RF, Medina M, Rigamonti $K$, Geckle DS, Pappas C: Cerebral venous malformations. J Neurosurg 73: 560-564, 1990

14) Rothfus WE, Albright AL, Casey KF, Latchaw RE, Roppolo HM: Cerebellar venous angioma: "benign" entity? AJNR Am J Neuroradiol 5: 61-66, 1984

15) Russell DS, Rubinstein LJ: Pathology of Tumors of the 
Nervous System, ed 4. Baltimore, Williams \& Wilkins, 1977, pp 116-145

16) Sadeh M, Shacked I, Rappaport ZH, Tadmor R: Surgical extirpation of a venous angioma of the medulla oblongata simulating multiple sclerosis. Surg Neurol 17: 334-337, 1982

17) Senegor M, Dohrmann GJ, Wollmann RL: Venous angiomas of the posterior fossa should be considered as anomalous venous drainage. Surg Neurol 19: 2632,1983

18) Uchino $A$, Hasuo $K$, Matsumoto $S$, Furukawa $T$, Matsuura Y, Fujii K, Fukui M, Masuda K: MR imaging and angiography of cerebral venous angiomas associated with brain tumors. Neuroradiology 34: 2529, 1992

19) Wilkins RH: Natural history of intracranial vascular malformations: a review. Neurosurgery 16: 421-430, 1985

20) Wilms G, Goffin J, Drissche JV, Demaerel PD: Posterior fossa venous anomaly and ipsilateral acoustic neuroma: two cases. Neuroradiology 34: 337-339, 1992

21) Wilms G, Marchal G, Hecke PV, Fraeyenhoven LV, Decrop E, Baert AL: Cerebral venous angiomas. MR imaging at 1.5 Tesla. Neuroradiology 32: 81-85, 1990

Address reprint requests to: T. Kamezawa, M.D., Department of Neurosurgery, Faculty of Medicine, Kagoshima University, 8-35-1 Sakuragaoka, Kagoshima 890-8520, Japan. 